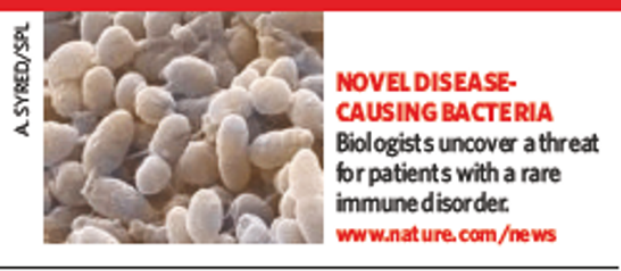

\title{
Lakes linked beneath Antarctic ice
}

The discovery that lakes hidden deep beneath the Antarctic ice could burst under pressure "like champagne corks" is prompting a rethink of plans to explore the watery world under the continent's four-kilometre-thick ice sheet. Any flooding might also make its way to the sea, a prospect that has sparked a debate about whether it could affect global climate.

Antarctica's subglacial lakes have attracted dose attention since researchers first realized, around a decade ago, that they may have been isolated for millions of years and so could harbour unique microbial ecosystems. But as awareness has grown, so have the disputes. Many researchers have objected to Russian plans to drill into one of the largest and beststudied bodies of water, Lake Vostok, fearing that it could become contaminated.

The new data, published on page 1033 of this issue, suggest that water from melting ice is pressurizing subglacial lakes, causing rivers with a flow equivalent to that of the Thames to form beneath the ice sheet. "Sooner or later the lakes will go off like champagne corks," says Duncan Wingham, a physicist at University College London and lead author on the study.

Wingham's ideas are based on changes in the height of the Antarctic ice sheet revealed by radar devices on the ERS-2 orbiting satellite. A 600-square-kilometre area of East Antarctica dropped by 3 metres in 1997. Around the same time, the ice at two regions $290 \mathrm{~km}$ east of this area rose by about a metre (see graphic).

Several lakes are known to exist in these regions, so Wingham and his colleagues con-

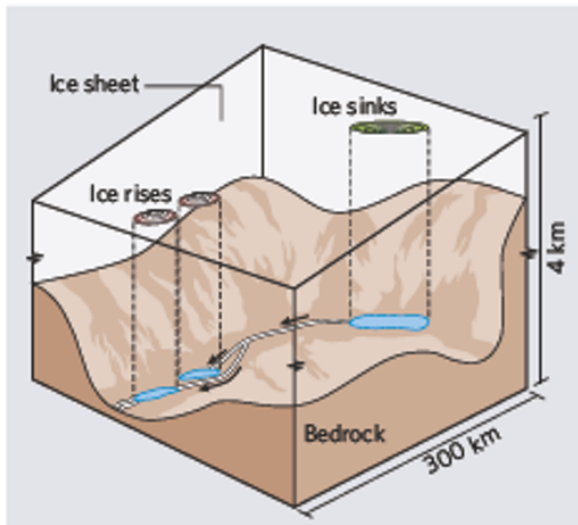

Satellite data showed ice sinking above one sub glacial lake, while rising at two spots $290 \mathrm{~km}$ away.

The researchers conclude that water must have flowed from the first lake into two others downstream.

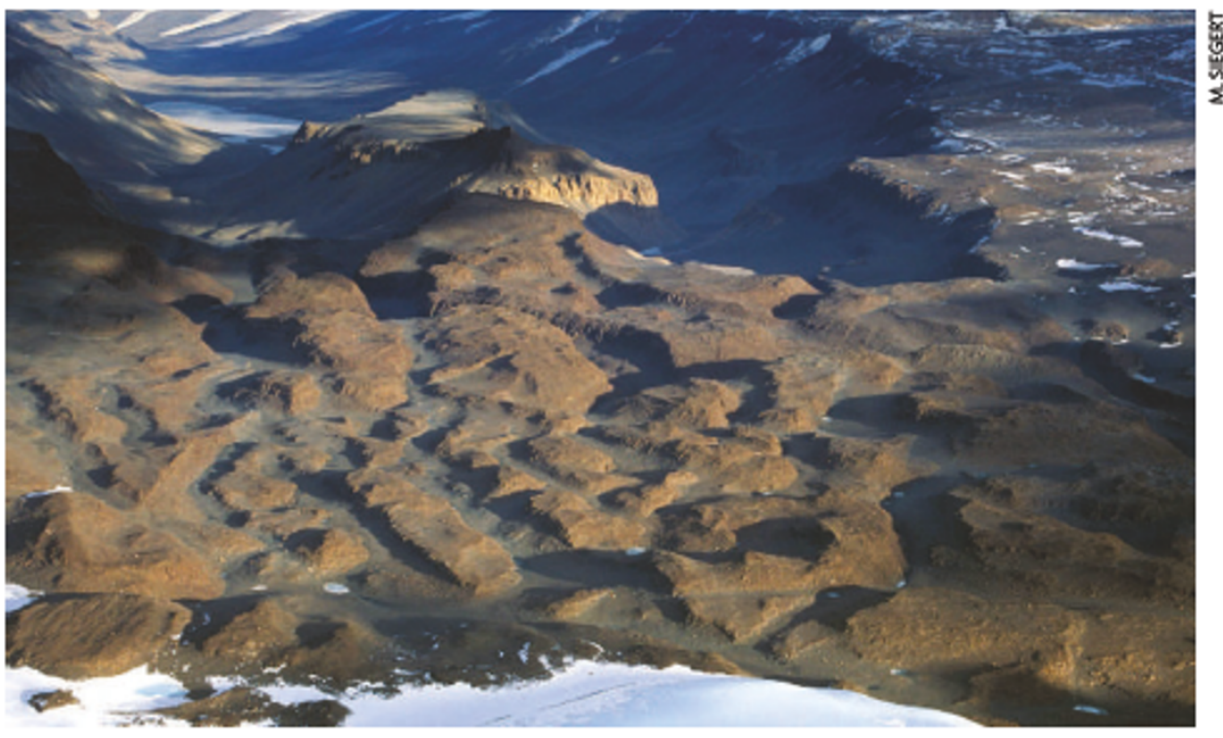

Channels in Antarctic rock suggest that subglacial lakes may once have drained into the sea.

clude that the changes are caused by about 1.8 cubic kilometres of water flooding between previously isolated lakes. They suggest that as melting ice flowed into the lakes, changes in pressure forced open tiny channels (see page 1000 ), causing a flood that lasted for about a year. As the flow subsided, the weight of ice closed the tunnel and sealed the lake again.

About 150 subglacial lakes have already been identified in Antarctica, but thousands more may exist, and the same process could affect them all. Wingham doubts whether all the lakes are connected, but says that some are linked like "beads on a string" by channels that periodically burst open.

If lakes such as Vostok were not isolated, they would be less interesting to researchers, although even if they are linked they could still share a unique ecosystem. And if they are connected, the risks associated with drilling increase. "If we accidentally contaminate one lake, will we contaminate a series of lakes via

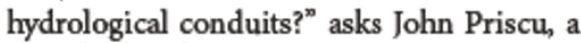
microbial ecologist at Montana State University in Bozeman, who studies subglacial lakes. He says Wingham's results should be considered when planning exploration projects.

US and European researchers are debating how best to minimize the risk of contamination, and don't expect to be ready to drill into a lake before the end of the decade. But a Russian team plans to enter Lake Vostok as early as
2007. That worries others, because the borehole, which currently ends 100 metres above the surface of the lake, contains drilling fluid that could potentially contaminate the water.

Valery Lukin of the Arctic and Antarctic Research Institute in St Petersburg, head of the Russian drilling efforts, says the Wingham paper "will not influence plans to drill into Vostok". Lukin says his team is confident that the pressure in Lake Vostok will force water up into the bore-
it will freeze and act as a cap to prevent contamination.

Researchers are also asking what would happen if a large subglacial lake discharged into the sea. Antarctica's edge has twisting channels in the rock that researchers believe were formed in the Miocene, 13 million years ago, by the drainage of subglacial lakes. David Marchant, a geologist at Boston University in Massachusetts, says the water would have drained into the ocean, where it could have disrupted circulation patterns and influenced global climate. So this process could conceivably occur again.

"It depends on the total volume of water that drains into the ocean and how fast it gets there," he says. To determine the risk, Marchant says that a better understanding of the timing and size of the Miocene floods and the climate changes of the period is needed. Researchers will also need to work out which modern lakes are connected.

Jim Giles 